Article

\title{
High-Resolution Climate Projections for a Densely Populated Mediterranean Region
}

\author{
Mohamed Salem Nashwan ${ }^{1,2}\left(\mathbb{C}\right.$, Shamsuddin Shahid ${ }^{2}(1)$ and Eun-Sung Chung ${ }^{3, *(1)}$ \\ 1 Department of Construction and Building Engineering, College of Engineering and Technology, \\ Arab Academy for Science, Technology and Maritime Transport (AASTMT), 2033 Elhorria, Heliopolis, \\ Cairo 2033, Egypt; m.salem@aast.edu \\ 2 School of Civil Engineering, Faculty of Engineering, Universiti Teknologi Malaysia (UTM), \\ Skudai 81310, Johor, Malaysia; sshahid@utm.my \\ 3 Faculty of Civil Engineering, Seoul National University of Science and Technology, 232 Gongneung-ro, \\ Nowon-gu, Seoul 01811, Korea \\ * Correspondence: eschung@seoultech.ac.kr
}

Received: 6 March 2020; Accepted: 28 April 2020; Published: 2 May 2020

\begin{abstract}
The present study projected future climate change for the densely populated Central North region of Egypt (CNE) for two representative concentration pathways (RCPs) and two futures (near future: 2020-2059, and far future: 2060-2099), estimated by a credible subset of five global climate models (GCMs). Different bias correction models have been applied to correct the bias in the five interpolated GCMs' outputs onto a high-resolution horizontal grid. The $0.05^{\circ} \mathrm{CNE}$ datasets of maximum and minimum temperatures (Tmx, and Tmn, respectively) and the $0.1^{\circ}$ African Rainfall Climatology (ARC2) datasets represented the historical climate. The evaluation of bias correction methodologies revealed the better performance of linear and variance scaling for correcting the rainfall and temperature GCMs' outputs, respectively. They were used to transfer the correction factor to the projections. The five statistically bias-corrected climate projections presented the uncertainty range in the future change in the climate of CNE. The rainfall is expected to increase in the near future but drastically decrease in the far future. The Tmx and Tmn are projected to increase in both future periods reaching nearly a maximum of 5.50 and $8.50^{\circ} \mathrm{C}$ for $\operatorname{Tmx}$ and $\mathrm{Tmn}$, respectively. These findings highlighted the severe consequence of climate change on the socio-economic activities in the CNE aiming for better sustainable development.
\end{abstract}

Keywords: Egypt; Nile Delta; ARC; general circulation model; CMIP5; downscaling

\section{Introduction}

Climate change has drastically affected the Mediterranean human and natural systems, including human health, agriculture, water management, and ecological diversity [1], making it one of the hotspots of climate change [2]. Increases in the magnitude and frequency of climate extremes have been observed in the recent decades [3-6] and are projected in the future [7-9].

Global climate models (GCMs) are usually used as a primary tool for studying the changes in the climate. In recent years, successive efforts have been made to simulate the global climate, and thus several models have been introduced in the fifth phase of the Coupled Models Intercomparison Project (CMIP5). They have been extensively used to project the future climate at global and regional levels $[10,11]$. Although GCMs can simulate the large-scale characteristics of climate, the credibility of their historical outputs of different climatic variables (e.g., temperature and rainfall) varies with the model used and the geographical location [12-16]. This is due to the challenges in simulating the characteristics of different climatic variables within different synoptic regimes [17]. Therefore, 
researchers usually select as many GCMs as possible to compensate for uncertainty in the intermodel variability [18]. The selected models should be capable of accurately representing the past climate of a certain region and encompass a wide diversity of future climate projections [19]. Nevertheless, typical GCMs present their outputs at coarse resolution spatial grids, which often have a $200 \mathrm{~km}$ spacing increment [20]. These coarse spatial girds are incompetent to represent the mesoscale features of local climates, which pose challenges for policymakers in making decisions concerning adaptation and mitigation measures. To bridge the spatial gap between the coarse-scale GCMs' outputs and the fine-scale information required, downscaling methods of climate variables have been developed.

The climate downscaling methods can be categorized into two main groups: the dynamical and statistical downscaling methods [21]. The main idea of the dynamical downscaling method is to simulate sub-GCMs' grid-scale features dynamically using a time-varying lateral atmospheric condition supplied by a GCM over a target domain [22], while the statistical downscaling method aims to establish a statistical relationship between the GCM outputs and the fine-scale variables using historical records [23]. Both methods are widely used as means of driving the local-scale climate from large-scale atmospheric predictor variables. However, the statistical downscaling methods are favourable as they are easy to implement and do not require high computational powers as are required for the dynamical downscaling methods $[20,23,24]$.

Egypt mostly depends on the water of the Nile river [25]. Its climate is characterized by low precipitation and high temperatures and evapotranspiration. Thus, the land of Egypt is subjected to the lack of natural vegetation, except for the Nile Delta and Valley, with zero values of the normalized difference vegetation index (NDVI) [26,27]. Due to the desert environment and the limited water availability, the country is highly vulnerable to the changes in climate [28-30]. Projected climate change in Egypt, and specifically its central north region (CNE), has received little attention. Most of the climate change studies focused on the effects of the rising level of seawater on the country [30-35]. Mostafa et al. [9] projected the change in rainfall and temperatures at eight stations in Egypt using the Coordinated Regional Climate Downscaling Experiment (CORDEX) Africa. Nashwan and Shahid [36] projected the change in rainfall and temperature signals using a set of credible GCMs over Egypt by a $2.5^{\circ} \times 2.5^{\circ}$ spatial grid. Furthermore, as Egypt is located at the edge of the Asian, African, and European CORDEX domains, it was presented in several continental-scale studies [37-39]. However, the magnitude of the climate change signal from the continental studies differs greatly from the regional average. Therefore, in order for policymakers to develop effective strategies to mitigate or adapt with climate change, it is necessary to project the future localized change in rainfall and temperatures, which shall be more representative of local needs.

To have creditable outputs of regional climates using statistical downscaling, credible historical observations are required. As gauge data are often scarce and spatially sparse in many regions in the world $[40,41]$, the high-resolution gridded datasets are often used for this aim. The high-resolution gridded datasets are mostly based on either satellite data and/or ground-based gauge measurements. The recent availably of the $0.05^{\circ}$ gridded Central North region of Egypt (CNE) datasets [42] of maximum and minimum temperatures ( $\operatorname{Tmx}$, and $\operatorname{Tmn}$, respectively), and the $0.1^{\circ}$ daily African Rainfall Climatology v.2 (ARC2) dataset [43] have enabled researchers to statistically downscale GCMs' outputs over the CNE, which is the most populated and economically vital region in Egypt. The present study took the initiative by statistically downscaling a set of five GCMs-which were found to be the most credible for Egypt [36] — to understand the specific characteristics of future temperatures and rainfall over this vulnerable region under the context of climate change. Several bias correction methods were evaluated for correcting the bias in GCMs' outputs compared to historical observations. The most robust methods were then selected for correcting the bias in future projections of climate under two future scenarios, and the change in future climate compared to the historical period were projected. This study shall provide insights to the future changes in rainfall and temperatures for this densely populated Mediterranean region. 


\section{Study Area and Data}

\subsection{Study Area}

Egypt is located to the far northeast of Africa with a land area of 1 million $\mathrm{km}^{2}$. It has long coastal fronts to the Mediterranean Sea and the Red Sea. The Nile River, which originates in central Africa, penetrates the country from the south and downstream in the Mediterranean. Figure 1 shows the lights of night-time captured over Egypt using the low-light imaging (day/night band) of the Visible Infrared Imaging Radiometer Suite (VIIRS) on the Suomi National Polar-orbiting Partnership satellite. The city lights (shades of grey colour) represents the unique population distribution along the Nile, which is one of the densest in the world, exceeding 2000 capita per $\mathrm{km}^{2}$ in some cities. Away from the lights, a uniform black presents the deserts and waters. Nearly $75 \%$ of the Egyptian population lives in the CNE [44]. The CNE (latitude: $29.50^{\circ}-31.55^{\circ}$; longitude: $29.50^{\circ}-33.00^{\circ}$, Figure 1 ) encompasses the Greater Cairo metropolitan area, the new administrative capital, and the Nile Delta and Suez Canal regions. This region is vital for the Egyptian economy because it is the land where most of the Egyptian cotton, rice, and wheat are planted, which represent $60 \%$ of the Egyptian agricultural land [45]. Furthermore, the region also houses most of the Egyptian industrial activities [46].

The climate of CNE, as well as Egypt, is a hot desert arid climate with two main seasons: summer from April to September and winter during the remaining months [47]. The summer is hot and dry, while the winter is cool and wet. Most of the rainfall occurs in the north and east of the country and the interior of the land is dry with a long-term annual mean rainfall of zero [48]. The temperatures vary between $22.3-35.0^{\circ} \mathrm{C}$ for $\operatorname{Tmx}$ and $10.0-22.5^{\circ} \mathrm{C}$ for $\mathrm{Tmn}$ through the year.

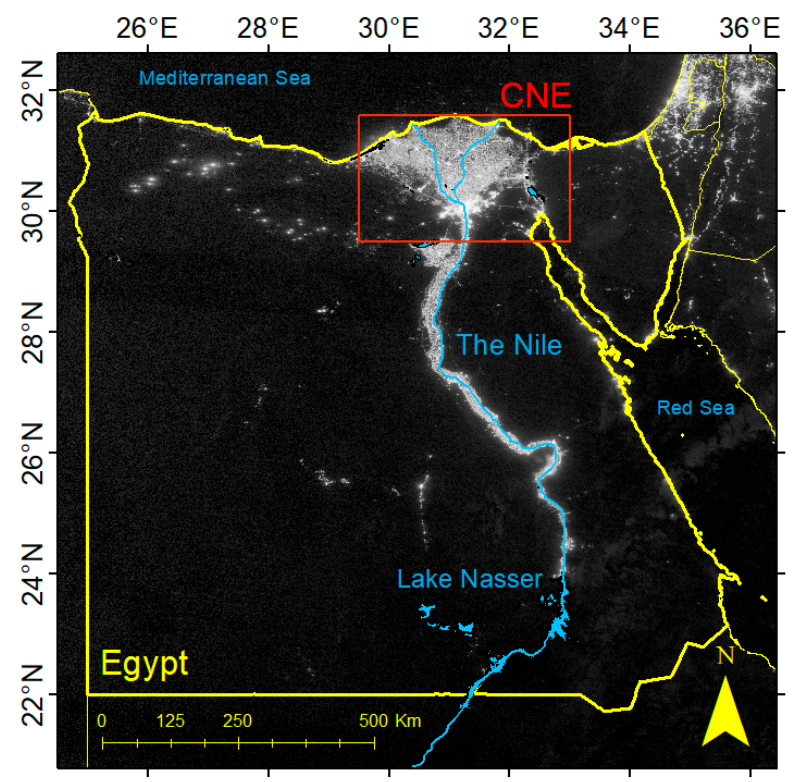

Figure 1. Night-time lights of Egypt captured by the Visible Infrared Imaging Radiometer Suite (VIIRS) on the Suomi National Polar-orbiting Partnership satellite. The night-time lights of Egypt reveal the unique distribution of its nearly 100 million capita in the Central North region of Egypt (CNE) (including the Nile Delta) and the Nile Valley.

\subsection{Observation Gridded Data}

Two high-resolution gridded datasets were used in this study to represent historical observed climate. They are the CNE temperatures dataset [42] and ARC2 rainfall dataset [43]. The CNE dataset provides daily estimates of Tmx and Tmn at $0.05^{\circ}$ spatial resolution from 1981 to 2017 in the CNE region [42]. It was developed through three steps. First, the Climate Prediction Center (CPC) global daily temperature dataset was interpolated into $0.05^{\circ} \times 0.05^{\circ}$ spatial grid. Second, the 
interpolated estimates were bias corrected with reference to station observation, using the robust kernel density distribution mapping (KDDM) method [49]. Third, the bias-corrected estimates where integrated with WorldClim v.2 high-resolution climatology datasets [50] to obtain the spatial pattern in temperature variability over the CNE. The CNE datasets were validated against independent ground observations and other gridded datasets such as University of Delaware (UDel) Air Temperature v5.01 and University of East Anglia Climatic Research Unit time series (CRU TS) v4.01 for monthly averages, and the climatologies at high resolution for the earth's land surface areas (CHELSA) v1.2 for monthly averages and climatology. The validation of CNE datasets (presented in [42]) proved their capability in reproducing the temporal and spatial variability in observed temperature. The CNE datasets of Tmx and Tmn are available online within the Figshare open access repository [51]. Figure 2 presents the annual average temperature during 1981-2005 estimated by the CNE datasets.

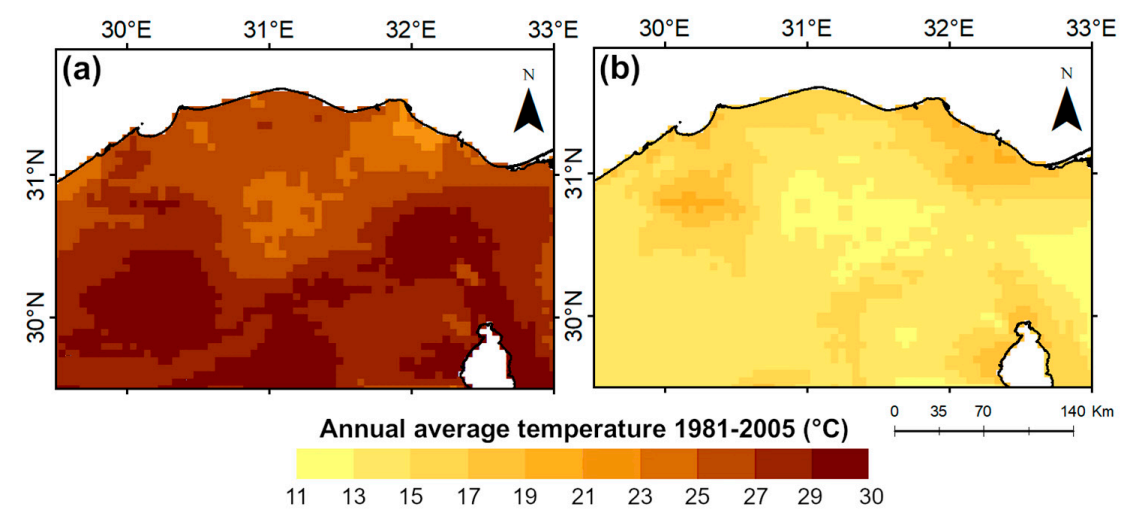

Figure 2. The spatial distribution of annual average (a) maximum temperature ( $\operatorname{Tm} x)$ and (b) minimum temperature (Tmn) during 1981-2005, estimated by the CNE datasets.

The ARC2 is a satellite-based gauge-corrected precipitation product that has been developed by the National Oceanic and Atmospheric Administration (NOAA) CPC. It has provided daily estimations of rainfall at $0.1^{\circ}$ spatial resolution since 1983, covering only Africa. It integrates the 3-hourly infrared data of Meteosat First Generation Satellites 2-7 (MFG2-7) and the Meteosat Second Generation (MSG 8-10) with daily rainfall observations of nearly 1200 in situ ground stations from the global telecommunication system gauge network [43]. The ARC2 data are freely available at the CPC website. ARC2 was compared against the observed rain gauge data in Egypt and showed an acceptable performance [52]. Figure 3 presents the annual average rainfall during 1983-2005 estimated by the ARC2 over the CNE region.

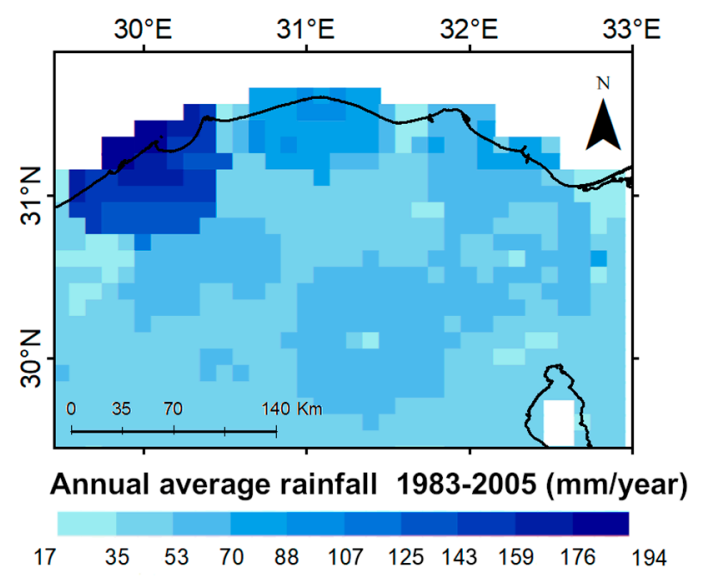

Figure 3. The spatial distribution of annual average rainfall during 1983-2005 estimated by the $0.1^{\circ}$ daily African Rainfall Climatology v.2 (ARC2) dataset. 


\subsection{Global Climate Models}

Five GCMs were statistically downscaled over the CNE region in this study. Table 1 presents a list of the GCMs, their developing centre, and raw spatial resolution. The five GCMs provide daily simulations of the climate and have the two representative concentration pathway (RCP) scenarios, RCP4.5 and RCP8.5. Those GCMs are the most credible GCMs for Egypt's climate [36]. They were selected based on a novel past performance evaluation and ranking framework from an initial pool of 31 CMIP5 GCMs [36]. The initial pool of GCMs considered only those having daily outputs of the three variables for at least RCP4.5 and RCP8.5 and have the "r1i1p1" initial condition. The evaluation and ranking framework focused on selecting models that can replicate the annual spatial patterns of Tmx, Tmn, and P accurately. Models that could not accurately replicate any of the three variables were not selected. The result of the evaluation and ranking can be summarized as (1) MRI-CGCM3 was the overall best model for the three variables; (2) FGOALS-g2 was the overall best in simulating temperatures and GFDL-CM3 for rainfall; (3) FGOALS-g2 had the lowest rank for rainfall; (4) GFDL-CM3 had the lowest rank for Tmx; and (5) the ranks of the other models-excluding GFDL-CM3 - were close to each other per variable. More details about the evaluation and ranking approach leading to the selection of the five GCMs are available in Nashwan and Shahid [36]. By using an intermediate stabilization scenario- $\mathrm{RCP} 4.5$ - and the highest possible climatic change scenario-RCP8.5, this study can be a lookout to a wide range of possible impacts of climate change for the CNE.

Table 1. The global climate models (GCMs) downscaled for the CNE.

\begin{tabular}{ccc}
\hline GCM & Developing Centre & Raw Spatial Resolution \\
\hline FGOALS-g2 & Institute of Atmospheric Physics, Chinese & $2.8^{\circ} \times 2.8^{\circ}$ \\
GFDL-CM3 & Academy of Sciences, China & $2.5^{\circ} \times 2.0^{\circ}$ \\
GFDL-ESM2G & Geophysical Fluid Dynamics Laboratory, USA & $2.5^{\circ} \times 2.0^{\circ}$ \\
MPI-ESM-MR & Maxphysical Fluid Dynamics Laboratory, USA & $1.9^{\circ} \times 1.9^{\circ}$ \\
MRI-CGCM3 & Meteorologitute for Meteorology, Rermany & $1.1^{\circ} \times 1.1^{\circ}$ \\
\hline
\end{tabular}

\section{Methodology}

The following steps were adopted in this study to downscale the five GCMs' outputs of Tmx, Tmn, and rainfall:

1. Regrid the GCMs' outputs to $0.1^{\circ}$ for rainfall and $0.05^{\circ}$ for temperatures-the same as the resolution of the observation datasets-using the bilinear interpolation technique.

2. Correct the bias in regridded GCM temperature/rainfall data for the historical period (1983-2005 for rainfall and 1981-2005 for temperatures) using CNE and ARC2 as reference datasets for temperatures and rainfall, respectively.

3. Evaluate the performance of different bias correction methods for rainfall and temperatures, separately, and select the best methods based on different statistical metrics.

4. Employ the best bias correction method in regridded projections of future rainfall and temperatures for the generation of high-resolution climate projections for the period 2020-2099.

Afterwards, the future projected data were used to assess the spatial and temporal changes in rainfall and temperatures for two future periods (near future: 2020-2059 and far future: 2060-2099) compared to the historical periods (1983-2005 for rainfall and 1981-2005 for temperature). The details of methods used for the downscaling and projection of climate in the CNE region are given below.

\subsection{Model Output Statistics Downscaling}

Statistical downscaling methods are categorized as stochastic weather generators, perfect prognosis, and model output statistics (MOS) [53]. Among them, the MOS approach has been most widely 
used in recent years for its better capacity in bias correction of GCM simulations [54-59]. In MOS, a relationship between the observed and the GCM simulated precipitation is developed for the reference period, which is then applied to correct the biases in future GCM simulations. The MOS method can correct GCM biases unequivocally and therefore, it is widely recommended for climate change projections $[11,60,61]$. Another advantage of the MOS method is that the reliability of climate projections does not change the climate signal in GCM simulations. Turco, et al. [61] evaluated the performance of the MOS method for downscaling extreme precipitation in a complex terrain in the Mediterranean climate and showed its capability in downscaling the extremes of precipitation. Studies by Turco et al. [62] and Castellano and DeGaetano [63] also reported the capability of MOS models in downscaling extreme precipitation.

Several bias correction methods have been developed and used in different studies [64-67]. In this study, three widely used bias correction methods were employed for the correction rainfall outputs (Table 2), namely linear scaling (LS), power transformation (PT), and empirical quantile mapping (EQM). For the correction of temperature outputs, the variance-scaling bias correction method was used instead of PT with the other two methods mentioned above. The bias correction methods are described in detail below. The downscaleR package of the $\mathrm{R}$ software was used for the bias correction of GCMs' outputs.

Table 2. Methods used for correction of biases in the GCMs' rainfall and temperature data.

\begin{tabular}{cc}
\hline Bias Correction for Rainfall & Bias Correction for Temperatures \\
\hline Linear Scaling (LS), & Linear Scaling (LS), \\
Power Transformation (PT), and & Variance Scaling (Var), and \\
Empirical Quantile Mapping (EQM) & Empirical Quantile Mapping (EQM) \\
\hline
\end{tabular}

\subsubsection{Linear Scaling}

The LS method, introduced by Lenderink, et al. [68], uses the difference in observed and simulated monthly mean data as a monthly correction factor, which is then applied to uncorrected daily data for correction of bias. The daily rainfall is corrected using Equation (1) and the daily temperatures are corrected using Equation (2).

$$
\begin{aligned}
& P_{c o r, m}=P_{\text {raw }, m} \times\left[\frac{\mu\left(P_{\text {obs }, m}\right)}{\mu\left(P_{\text {raw }, m}\right)}\right] \\
& P_{\text {cor }, m}=P_{\text {raw }, m} \times\left[\frac{\mu\left(P_{\text {obs }, m}\right)}{\mu\left(P_{\text {raw }, m}\right)}\right]
\end{aligned}
$$

where $P_{c o r, m}$ and $T_{c o r, m}$ are the corrected precipitation and temperature of $m$ month, $P_{\text {raw }, m}$ and $T_{\text {raw }, m}$ are the same as previous but for raw interpolated GCM data, $P_{o b s, m}$ and $T_{o b s, m}$ are the precipitation and temperature observation data of $m$ month, and $\mu$ represents the mean.

LS is a simple method that requires only monthly data to calculate the scaling factor [69]. However, Diaz-Nieto and Wilby [70] and Maraun et al. [71] found that in the case of precipitation, the correction using only the monthly mean can distort intermonthly precipitation distribution and the probability distribution of monthly precipitation.

\subsubsection{Empirical Quantile Mapping}

EQM, introduced by Piani et al. [72], is a nonparametric bias correction method that can be applied to any kind of climatic variables, thus it can be used for both temperature and precipitation. Its main idea is based on constructing daily empirical cumulative distribution functions (eCDFs). The main difference between EQM and other distribution mapping-based methods is that the others focus on precipitation by estimating the eCDFs only for wet days. Thus, they cannot be used for temperature time series. EQM considers both mean and extreme values, so it is considered as one 
of the most efficient bias correction methods for precipitation [72-74]. The adjustment of rainfall or temperature using EQM can be expressed in terms of the eCDF and its inverse (eCDF-1), as formulated in Equations (3) and (4), respectively.

$$
\begin{aligned}
& P_{\text {cor }, m}=e C D F_{o b s, m}^{-1} \cdot\left[e C D F_{\text {raw }, m}\left(P_{\text {raw }, m}\right)\right] \\
& T_{\text {cor }, m}=e C D F_{o b s, m}^{-1} \cdot\left[e C D F_{\text {raw }, m}\left(T_{\text {raw }, m}\right)\right] .
\end{aligned}
$$

\subsubsection{Power Transformation}

Though the LS method is capable of correcting the bias in mean precipitation, it does not consider correcting the biases in the variance of time series. Thus, PT considers the bias in the mean and the differences in the variance for the correction of model outputs [75]. In PT, a nonlinear correction in the exponential form, $a . P^{b m}$, can be used for the adjustment of variance. Parameter $b_{m}$ is determined iteratively [76] by matching the coefficient of variation (CV) of daily GCM precipitation with the $\mathrm{CV}$ of observed daily precipitation for each month. This is carried out using Brent's method [77] of root-finding algorithm. The parameter $b_{m}$ is only a function of $C V$ as presented in Equation (5), and $a$ is the ratio of the mean of the observed and the mean of the transformed $\left(P_{r a w, m}^{b m}\right)$ values. Thus, parameter $a$ depends upon $b_{m}$ and not vice versa [78]. Then, the raw precipitation is transformed into corrected precipitation using Equation (6).

$$
\begin{aligned}
& \text { Find } b_{m} \text { such that } f\left(b_{m}\right)=0=C V\left(P_{o b s, m}\right)-C V\left(P_{\text {raw }, m}^{b m}\right) \\
& \qquad P_{c o r, m}=\left[\frac{\mu\left(P_{o b s, m}\right)}{\mu\left(P_{r a w, m}^{b m}\right)}\right] \times P_{r a w, m}^{b m} .
\end{aligned}
$$

\subsubsection{Variance Scaling}

Though the PT method can correct both the mean and variance in precipitation time series, it is not suitable for correcting the bias in temperature time series as temperature time series are known to be approximately normally distributed [79]. Therefore, the Var method was proposed to correct the bias in normally distributed variables, such as temperature, by correcting both the mean and variance [79]. In Var, the temperature is bias-corrected using the following equation where $\sigma$ is the standard deviation.

$$
T_{c o r, m}=\left[T_{\text {raw }, m}-\mu\left(T_{\text {raw }, m}\right)\right] \times \frac{\sigma\left(T_{o b s, m}\right)}{\sigma\left(T_{\text {raw }, m}\right)}+\mu\left(T_{o b s, m}\right) .
$$

\subsection{Evaluation Metric}

The performance of each bias correction method was evaluated upon the basis of the capability to generate the distribution of the historical reference data. The probability distribution function skill score (PDFss) was used as an evaluation metric. The PDFss is a robust score that measures the overlap between the bias corrected and the observed probability distribution functions (PDFs) by computing the cumulative minimum value of their distributions [80], as in Equation (8). It ranges from 0-1 and 1 indicates a perfect distribution overlap. Based on the evaluation results, the best bias correction method was selected to bias-correct future projections of all GCMs' outputs, separately. One bias correction method was selected for rainfall data correction and another for both Tmx and Tmn.

$$
P D F_{S S}=\sum_{1}^{n} \min \left(Z_{y}, Z_{x}\right)
$$


where $Z_{y}$ and $Z_{x}$ are the ratios of the values for a given $n$ number of bins from the observed and GCM PDFs, respectively.

\section{Results}

The daily rainfall and temperature outputs of the selected five GCMs were regridded into a fine resolution (i.e., $0.1^{\circ}$ for rainfall and $0.05^{\circ}$ for temperatures) over the $\mathrm{CNE}$ region using bilinear interpolation. Then, different bias correction models were developed to correct the bias in rainfall and temperatures data using ARC2 and CNE, respectively, as historical reference datasets. The bias correction methods were then evaluated to select the best method for correcting rainfall data and another for the temperatures data. The following is the evaluation results.

\subsection{Evaluation of Bias Correction Methods}

The performance evaluation of the different bias correction methods using box plots is given in Figure 4. The evaluation was carried out by comparing the bias-corrected downscaled output of the GCM historical simulation against the reference datasets at each grid. Each box represents the statistical metric obtained for a GCM using a particular bias correction method. The results revealed that all the bias correction methods were capable of improving the raw GCMs simulations to varying degrees. In general, all the bias correction methods performed better for temperatures than for rainfall. In case of rainfall, the LS outperformed the EQM and PT in term of median PDFss. However, the LS was found to be the worst method in the case of temperatures. The three methods were more capable in bias-correcting Tmn than Tmn in terms of PDFss. The Var method showed better PDFss than EQM for both Tmx and Tmn. Based on the evaluation results, the LS and Var methods were selected as the best methods for correcting bias in rainfall and temperatures, respectively in the CNE.
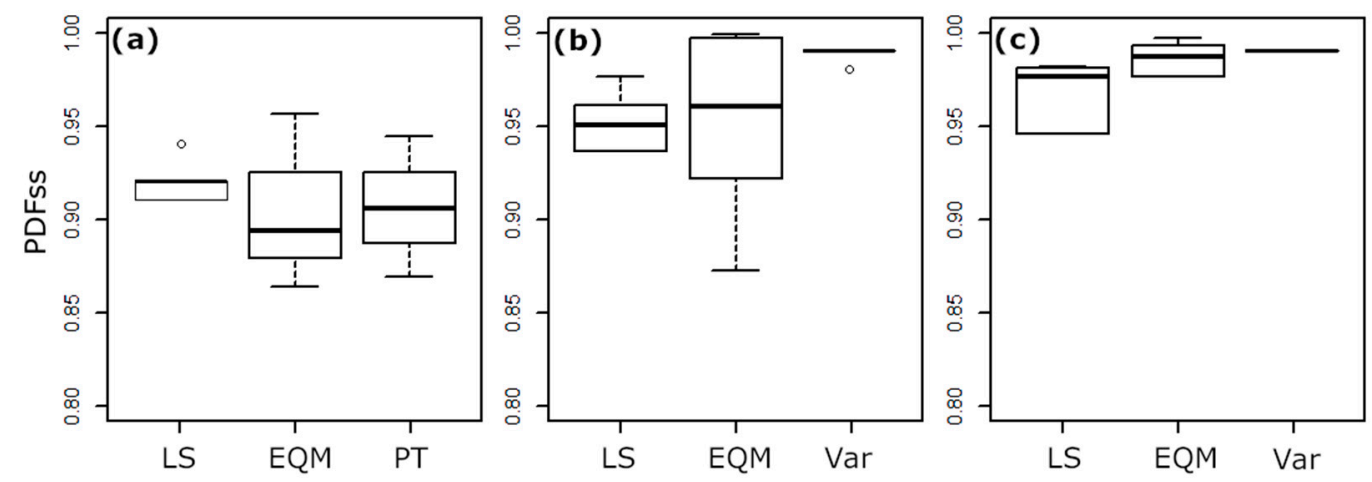

Figure 4. Box plots of probability distribution function skill score (PDFss) of different bias correction methods used for correcting the five GCMs estimates of (a) rainfall, (b) Tmx, and (c) Tmn.

Figure 5 presents the scatter plots of the raw and bias-corrected monthly rainfall and temperatures for five GCMs using linear and variance scaling, respectively, against historical observations. The figure shows that the bias-corrected values (red dots) are more aligned with the observations than the raw GCM outputs (blue dots). Although the LS models were found to improve the rainfall estimation of the downscaled GCMs considerably, the scatter plots indicate that the LS model overestimated the low rainfall amounts, while it underestimated extreme rainfall amounts. The large mismatch in rainfall was due to the large bias in GCM rainfall. The bias in GCM raw rainfall is also highly nonlinear (Figure 5). Therefore, correction of such bias was not possible by comparing the mean, variability, or distribution of GCM rainfall with the observed rainfall. On the contrary, the corrected Tmx and Tmn using the variance scaling model were found to be almost perfectly alligned with the CNE datasets' estimates. It was capable of correcting the over- and underestimated raw temperatures of the different GCMs. The bias in GCM temperature was found to be less and linear (Figure 5). Therefore, the bias correction model was able to correct it perfectly. 

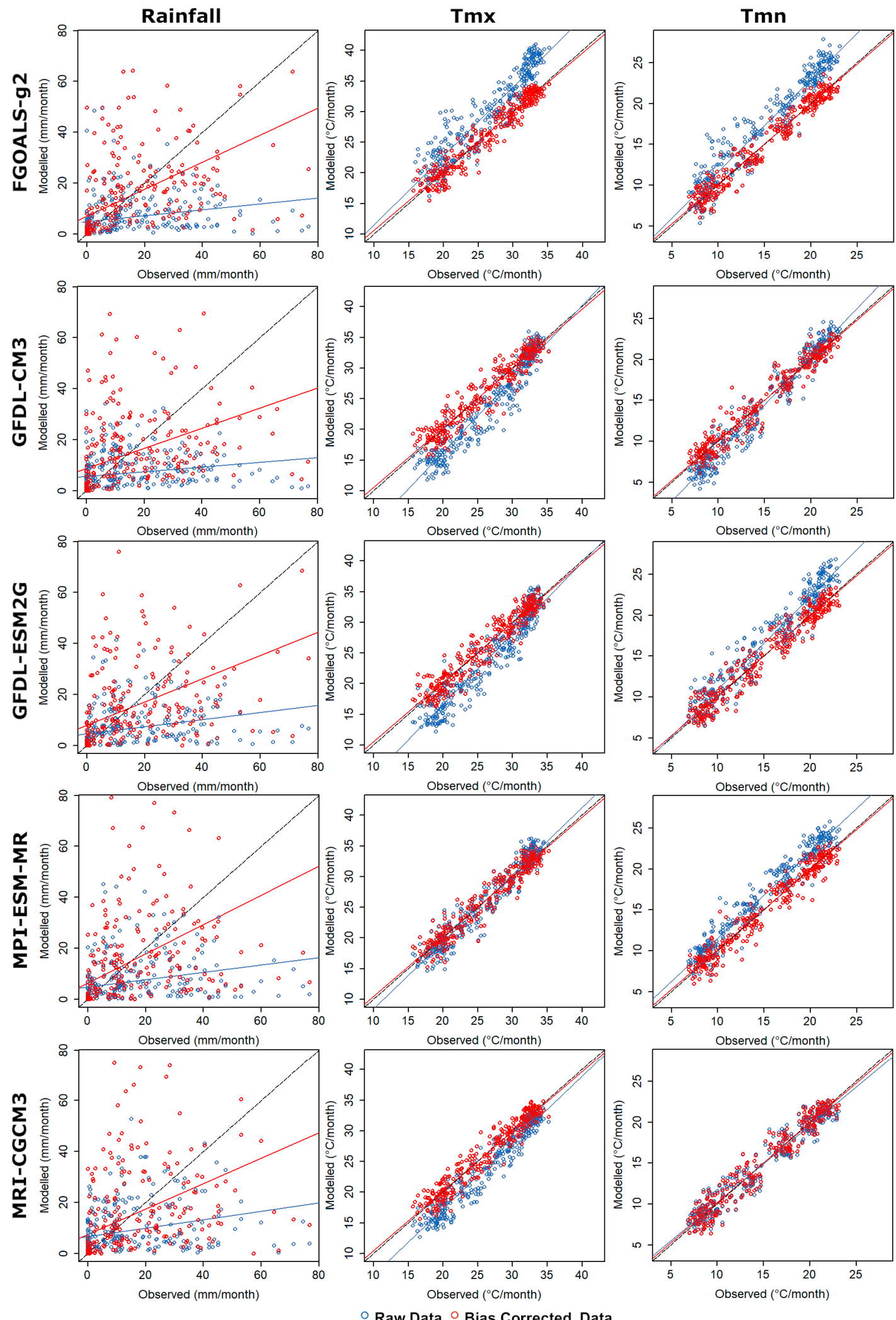

Figure 5. Scatter plots of the monthly observed R, Tmx, and Tmn against raw and downscaled GCM estimates. The columns of the panel represent the scatter plots of $\mathrm{P}, \mathrm{Tmx}$, and Tmn, and each row of the panel presents the scatter plot of the corresponding GCM. The black line represents the ideal line, while the blue and red lines represent the regression lines of the raw and downscaled GCM estimates, respectively. 
The good performance of both models was also observed using the density plots presented in Figure 6. It clearly shows the improvement in the bias-corrected estimations (red colour) in replicating the PDF of the observations (black colour) compared to the PDF of raw GCM estimations (blue colour). The PDFss values (presented in Table 3) represent the overlap between the PDFs of the bias-corrected and the observed time series (presented in Figure 5). The PDFss of the downscaled Tmx and Tmn were almost perfect (0.99) while they were high for rainfall in the range of 0.91-0.94.
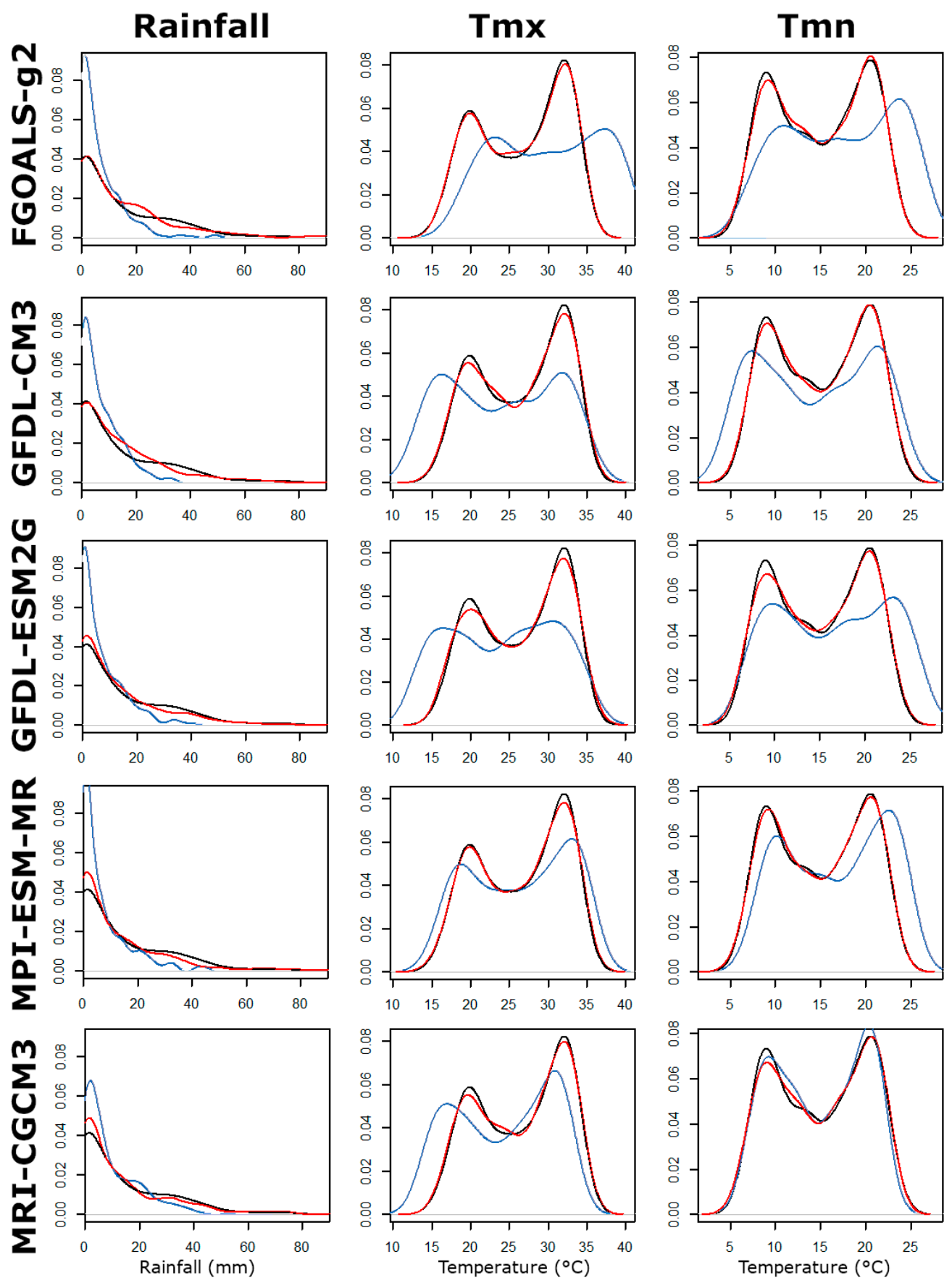

- Historical

- Raw Data Bias Corrected Data

Figure 6. Density plots of the monthly observed data, and the raw and downscaled GCM estimates of $\mathrm{P}, \mathrm{Tmx}$, and Tmn (columns). Each row of the panel presents the density plot of the corresponding GCM. The rainfall and temperatures estimates were bias-corrected using linear and variance scaling methods, respectively. 
Table 3. The PDFss of different bias-corrected GCMs in replicating observed PDF.

\begin{tabular}{cccc}
\hline GCM & Rainfall & Tmx & Tmn \\
\hline FGOALS-g2 & 0.94 & 0.99 & 0.99 \\
GFDL-CM3 & 0.92 & 0.99 & 0.99 \\
GFDL-ESM2G & 0.92 & 0.98 & 0.99 \\
MPI-ESM-MR & 0.91 & 0.99 & 0.99 \\
MRI-CGCM3 & 0.94 & 0.99 & 0.99 \\
\hline
\end{tabular}

\subsection{Projected Change in Spatial Patterns of the Climate Variables}

The projected changes in Tmx, Tmn, and P for two futures (i.e., near future: 2020-2059 and far future: 2060-2099) for RCP4.5 and RCP8.5 compared to the base period, 1981-2000 for temperatures and 1983-2000 for rainfall were estimated from the downscaled and bias-corrected GCM simulations. The bias-corrected GCM projections using LS for rainfall and Var for temperatures are only presented here as those methods were found best in correcting biases in GCM rainfall and temperature simulations, respectively. Figure 7 presents the spatial patterns in the change in the annual mean of daily Tmx projected by different GCMs during the near and far futures for the two RCPs. Each of the five downscaled and bias-corrected GCMs showed a distinct spatial pattern; however, most of them projected a higher increase of Tmx in the east and southeast of the CNE. A higher increase of Tmx in the far future than the near future was also projected. The average increase of $\operatorname{Tmx}$ in the near future was projected to be $1.13^{\circ} \mathrm{C}$ and $1.45^{\circ} \mathrm{C}$ for RCP4.5 and RCP8.5, respectively, while $1.80^{\circ} \mathrm{C}$ and $3.48^{\circ} \mathrm{C}$ in the far future. The GFDL-CM3 and GFDL-ESM2G estimated the highest and lowest change in Tmx, respectively. GFDL-CM3 projected a median increase of $1.83{ }^{\circ} \mathrm{C}$ and $2.94{ }^{\circ} \mathrm{C}$ for $\mathrm{RCP} 4.5$ and $2.34{ }^{\circ} \mathrm{C}$ and $4.50^{\circ} \mathrm{C}$ for RCP8.5 during the two futures, respectively. MRI-CGCM3 projected an increase in Tmx by $0.96{ }^{\circ} \mathrm{C}$ and $1.43^{\circ} \mathrm{C}$ for RCP4.5 and $1.18{ }^{\circ} \mathrm{C}$ and $2.71{ }^{\circ} \mathrm{C}$ for RCP8.5.

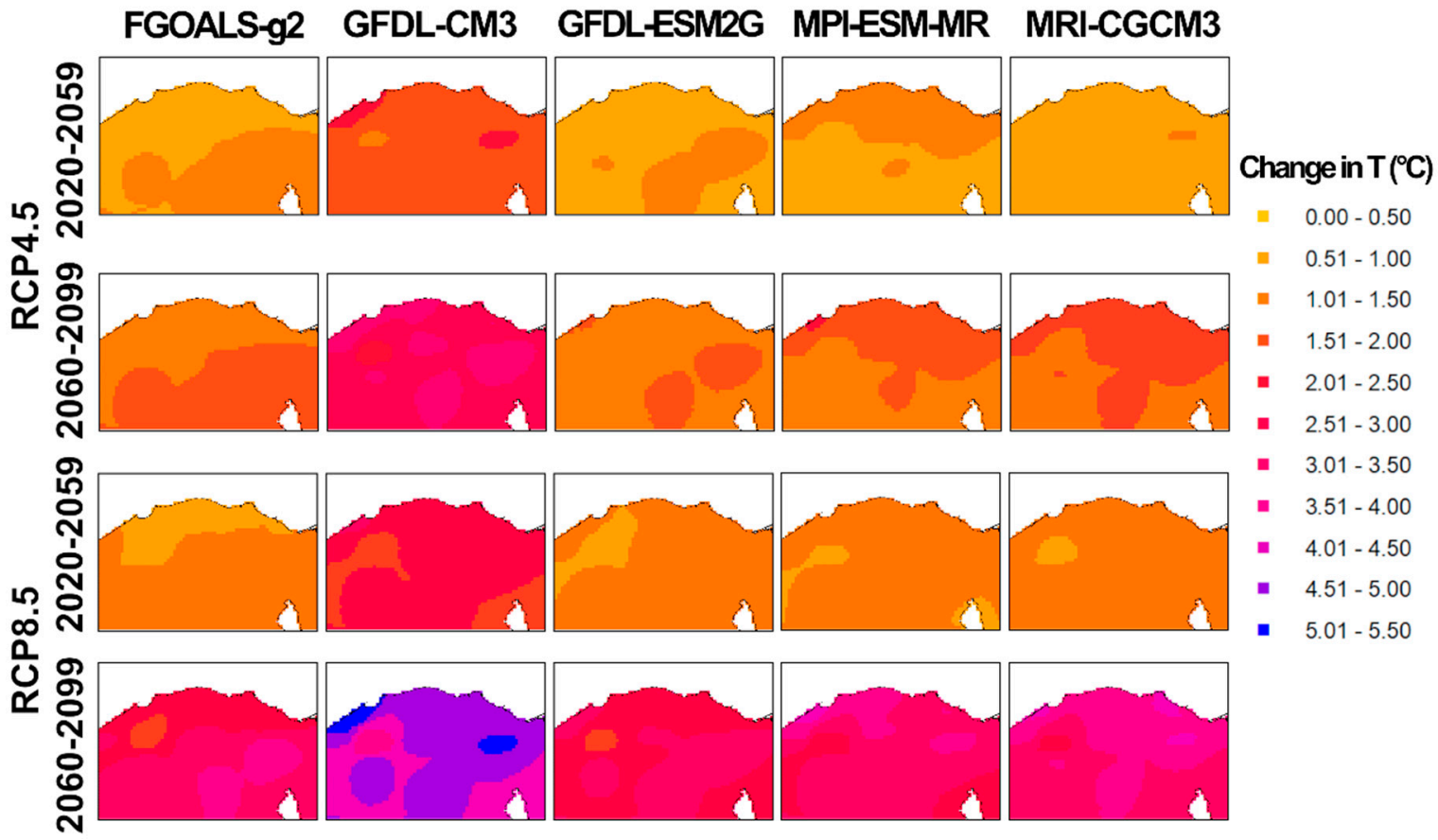

Figure 7. Changes $\left({ }^{\circ} \mathrm{C}\right)$ in the annual mean of daily maximum temperature for the periods 2020-2059 and 2060-2099 projected by the selected GCMs for RCP4.5 and RCP8.5 scenarios.

The spatial patterns in the projected increase of Tmn by the selected GCMs are presented in Figure 8. Unlike Tmx, the bias-corrected GCM projections showed a similar spatial pattern in the change of Tmn, but with different magnitude. The increase of Tmn in the north of the CNE region was 
projected to be more intense than in the south. The average increase in the near future was projected to be $1.23{ }^{\circ} \mathrm{C}$ and $1.58^{\circ} \mathrm{C}$ for RCP4.5 and RCP8.5, respectively, while $1.88^{\circ} \mathrm{C}$ and $3.49{ }^{\circ} \mathrm{C}$ in the far future. The GFDL-CM3 and GFDL-ESM2G estimated the highest and lowest changes in Tmn, respectively. GFDL-CM3 projected a median increase of $2.21^{\circ} \mathrm{C}$ and $3.23^{\circ} \mathrm{C}$ for $\mathrm{RCP} 4.5$, and $2.76{ }^{\circ} \mathrm{C}$ and $5.24{ }^{\circ} \mathrm{C}$ for RCP8.5 during the two future periods, respectively. MRI-CGCM3 projected an increase in Tmx by $0.90{ }^{\circ} \mathrm{C}$ and $1.40{ }^{\circ} \mathrm{C}$ for RCP4.5 and $1.17{ }^{\circ} \mathrm{C}$ and $2.72{ }^{\circ} \mathrm{C}$ for RCP8.5 for the near and far futures, respectively. The GFDL-CM3 projected the highest increase $\left(8.43^{\circ} \mathrm{C}\right)$ of Tmn in the far future for RCP8.5 in a small area in the northeast of CNE that coincides with the 2nd largest city in Egypt, Alexandria.

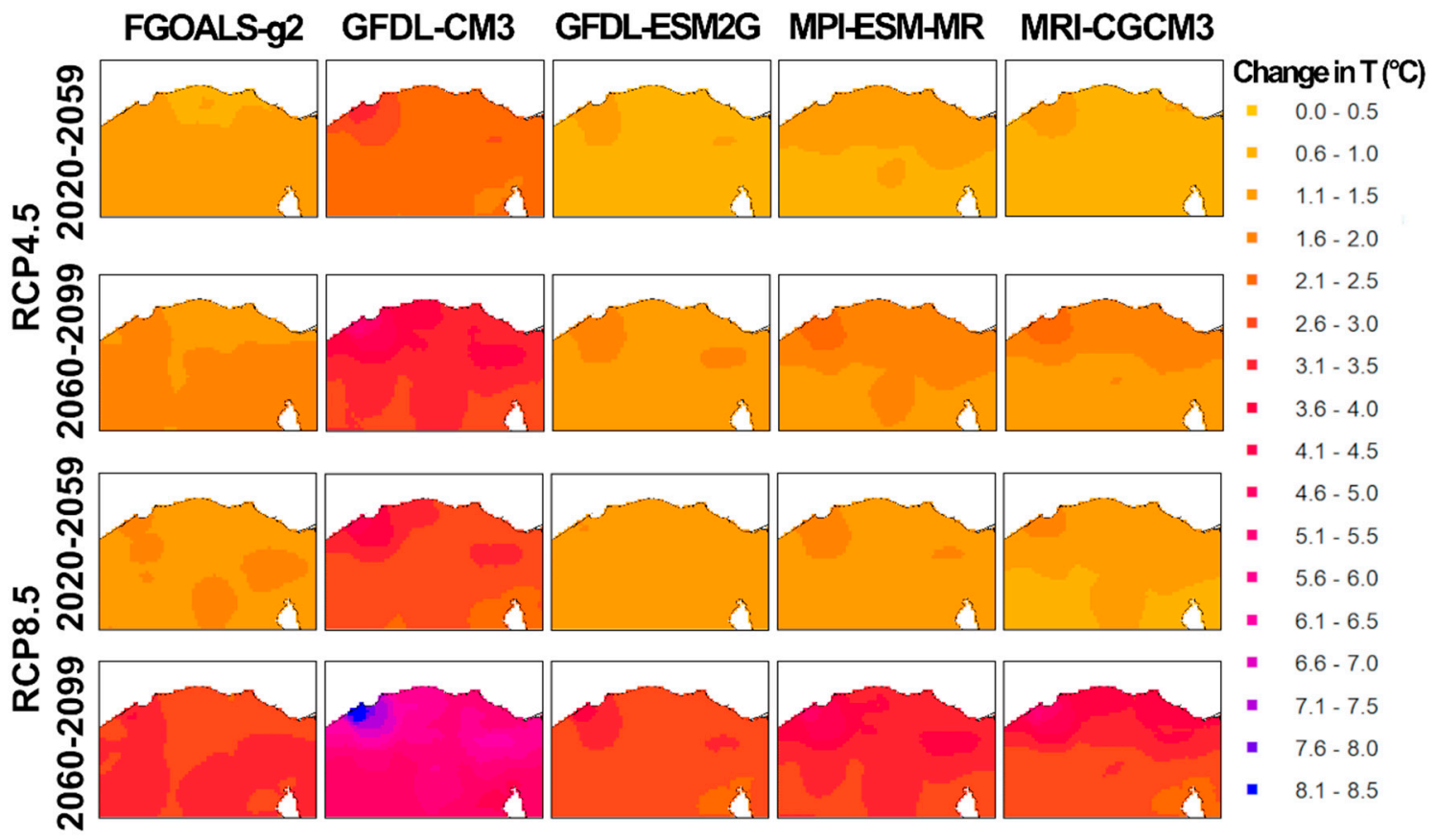

Figure 8. Changes $\left({ }^{\circ} \mathrm{C}\right)$ in the annual mean of daily minimum temperature for the periods 2020-2059 and 2060-2099 projected by the selected GCMs for RCP4.5 and RCP8.5 scenarios.

The spatial pattern in the percentage of change in rainfall over the CNE projected by the selected and bias-corrected GCMs is presented in Figure 9. Most GCMs projected an increase of rainfall in both the near and the far futures (mean change $45.04 \%$ and $36.51 \%$, respectively) under RCP4.5. However a decrease in rainfall was projected for both periods (mean change: $-95.46 \%$ and $-96.04 \%$, respectively) under RCP8.5. All the GCMs except GFDL-CM3 projected a higher increase of rainfall in the south than in the north of CNE for RCP4.5. FGOALS-g2 estimated the highest increase in rainfall by $200 \%$ and 182\% for RCP4.5 during the near and far futures, respectively. Also, all the GCMs estimated a common decrease in rainfall amount under RCP8.5 with nearly the same spatial patterns. GFDL-CM3, the top-ranked GCM for rainfall projected a 9.15\% increase of rainfall in the near future and $12.60 \%$ decrease in the far future for RCP4.5. For RCP8.5, 96.71\% and 97.00\% decreases of rainfall in the near and far futures, respectively, were projected. 


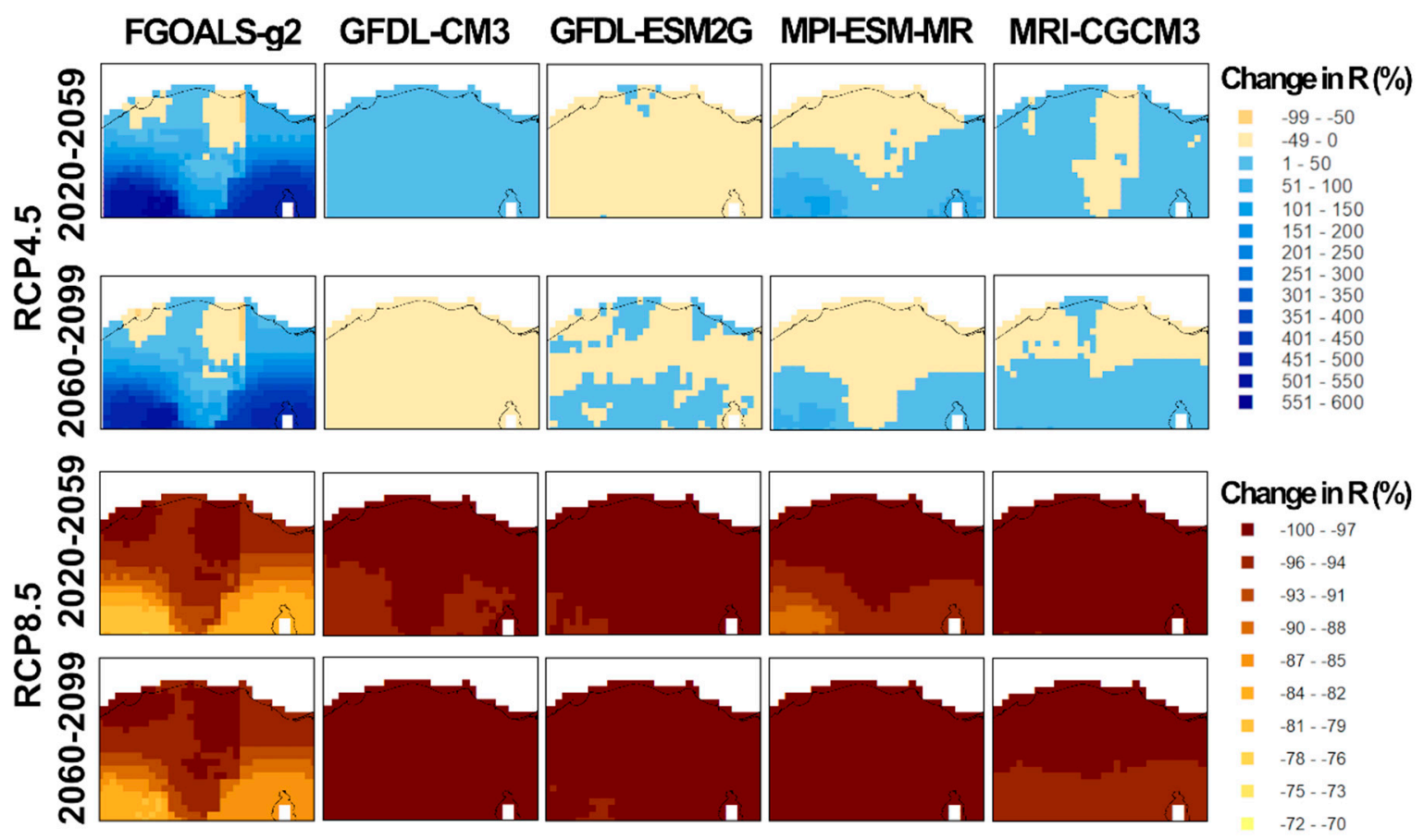

Figure 9. Changes (\%) in the annual mean rainfall for the periods 2020-2059 and 2060-2099 projected by the selected GCMs for RCP4.5 and RCP8.5 scenarios.

\subsection{Projected Regional Changes}

The regional changes in rainfall against temperature in the CNE during the near and far futures for the two RCP scenarios are presented in Figure 10 as a scatter plot. Rainfall change is presented by calculating the median change in rainfall estimated by each bias-corrected GCM for different periods and scenarios, while the temperature change is presented by calculating the average of the median changes in Tmx and Tmn estimated by each bias-corrected GCM. Each symbol in the plot indicates a GCM. The grey-colored symbols represent the changes for RCP4.5 and the dark blue represent the changes for RCP8.5. The symbols of red outline represent the changes in the far future and those without a color outline represent the changes in the near future. The intersection between the points of the same future period and RCP were connected to generate boundaries of future changes and to present the uncertainty in projections by the ensemble of GCMs. As shown in the figure, each GCM showed different mean changes in rainfall and temperature. The mean projected changes in temperature ranged between $0.92{ }^{\circ} \mathrm{C}$ and $3.08{ }^{\circ} \mathrm{C}$ for RCP4.5 and $1.17^{\circ} \mathrm{C}$ and $4.87^{\circ} \mathrm{C}$ for RCP8.5. Furthermore, the mean projected changes in rainfall were between $-12 \%$ and $114 \%$ for RCP 4.5 and $-93 \%$ and $-98 \%$ for RCP8.5. GFDL-CM3 projected the driest and hottest future changes for RCP4.5 and RCP8.5 scenarios. The boundary of future changes for RCP4.5 (highlighted in blue shades) was found to be much bigger than that for RCP8.5 (highlighted in red shades), indicating that the changes of rainfall projected under RCP4.5 using the selected GCMs were more uncertain compared to those under RCP8.5, while it was vice versa for temperatures. 


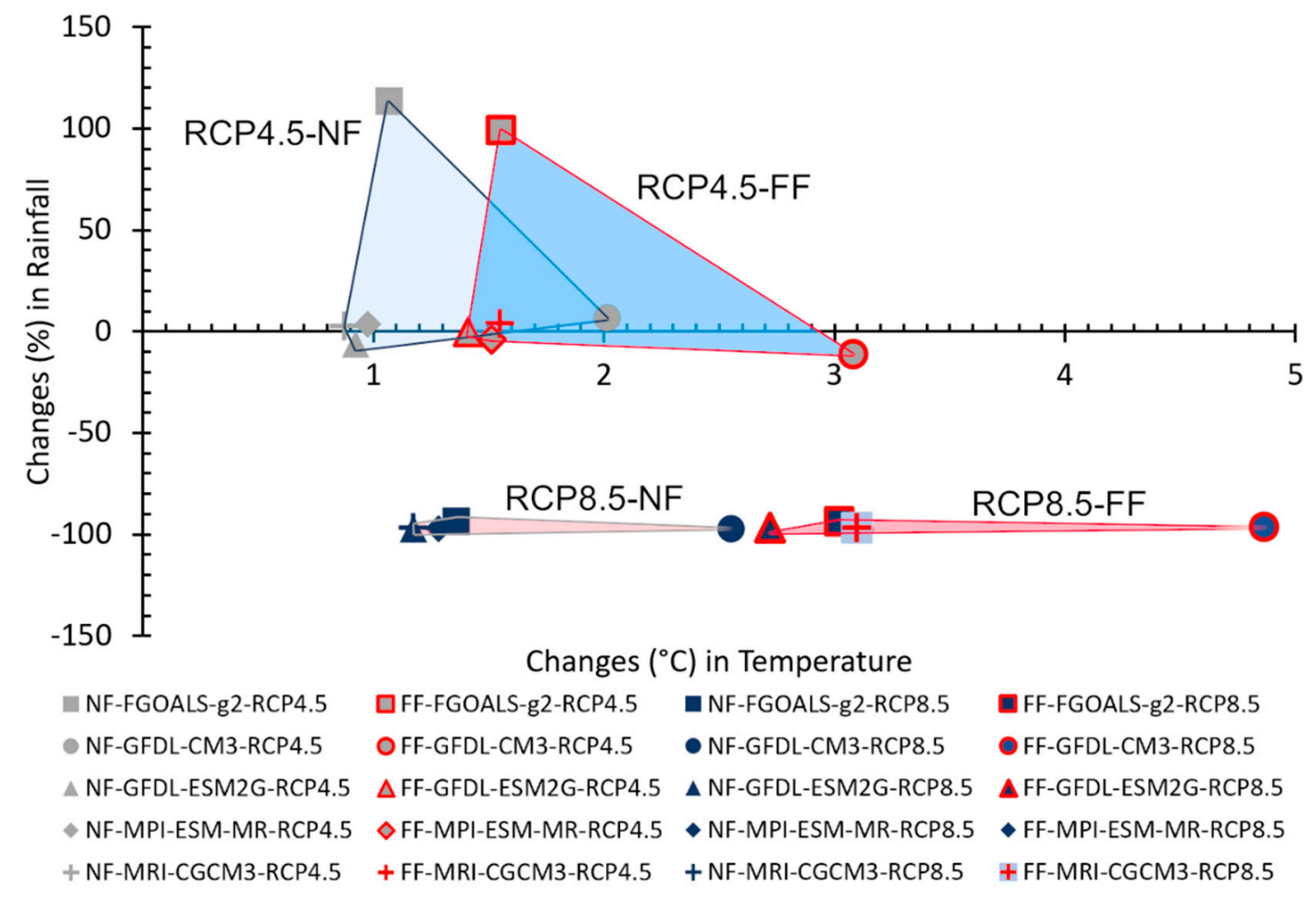

Figure 10. Scatter plot showing the regional change in rainfall $(\%)$ and temperature $\left({ }^{\circ} \mathrm{C}\right)$ for the $\mathrm{CNE}$ estimated for the near and far futures (NF, and FF, respectively) for two RCP scenarios.

\subsection{Projection Change in the Climate Variables Distribution}

Density plots of the historical and bias corrected projected annual P, and monthly Tmx and Tmn data for different GCMs under RCP4.5 and RCP8.5 scenarios are presented in Figure 11. The aim of presenting these plots is to display the change in distribution between the projected and historical data. They were calculated for the areal average rainfall and temperature. Furthermore, the PDFss were calculated to measure the overlap in PDFs of the historical and projected data for RCP4.5 and RCP8.5 for the two future periods. Then, the differences in PDFs (1-PDFss) were calculated and presented in Figure 12 to provide quantitate values of the projected distributional changes in rainfall and temperatures.

For rainfall, all GCMs, except FGOALS-g2, projected nearly the same annual distribution of rainfall in the two future periods under both RCP scenarios yet the changes projected under RCP8.5 were more than those under RCP4.5. This was indicated by the low values of the PDFss difference (=1-PDFss) for the four GCMs, as shown in Figure 12a,b. For FGOALS-g2, a decrease in the number of "less wet" years was projected for both the future periods and scenarios. The downscaled MPI-ESM-MR projected an increase in the number of "less wet" years under RCP8.5 for the far future. For RCP4.5, the distributions of the annual rainfall of the GFDL-ESM2G and GFDL-CM3 models were projected to change more during the far future than the near future, as presented in Figure 12a,b. But for RCP8.5, the PDFs of MRI-CGCM3 and FGOALS-g2 for the far future were projected to change more compared to the near future, while it was vice versa for the remaining models.

For temperature, the models showed nearly similar distributions for Tmx and Tmn compared to the historical periods, but shifted to the right indicating hotter climate, as presented in Figure 11. Also, they projected a gradual change in temperature distribution, Figure $12 \mathrm{c}-\mathrm{f}$, as the differences in PDFs between the projected near-future data and historical data were less than those for the far future data. 

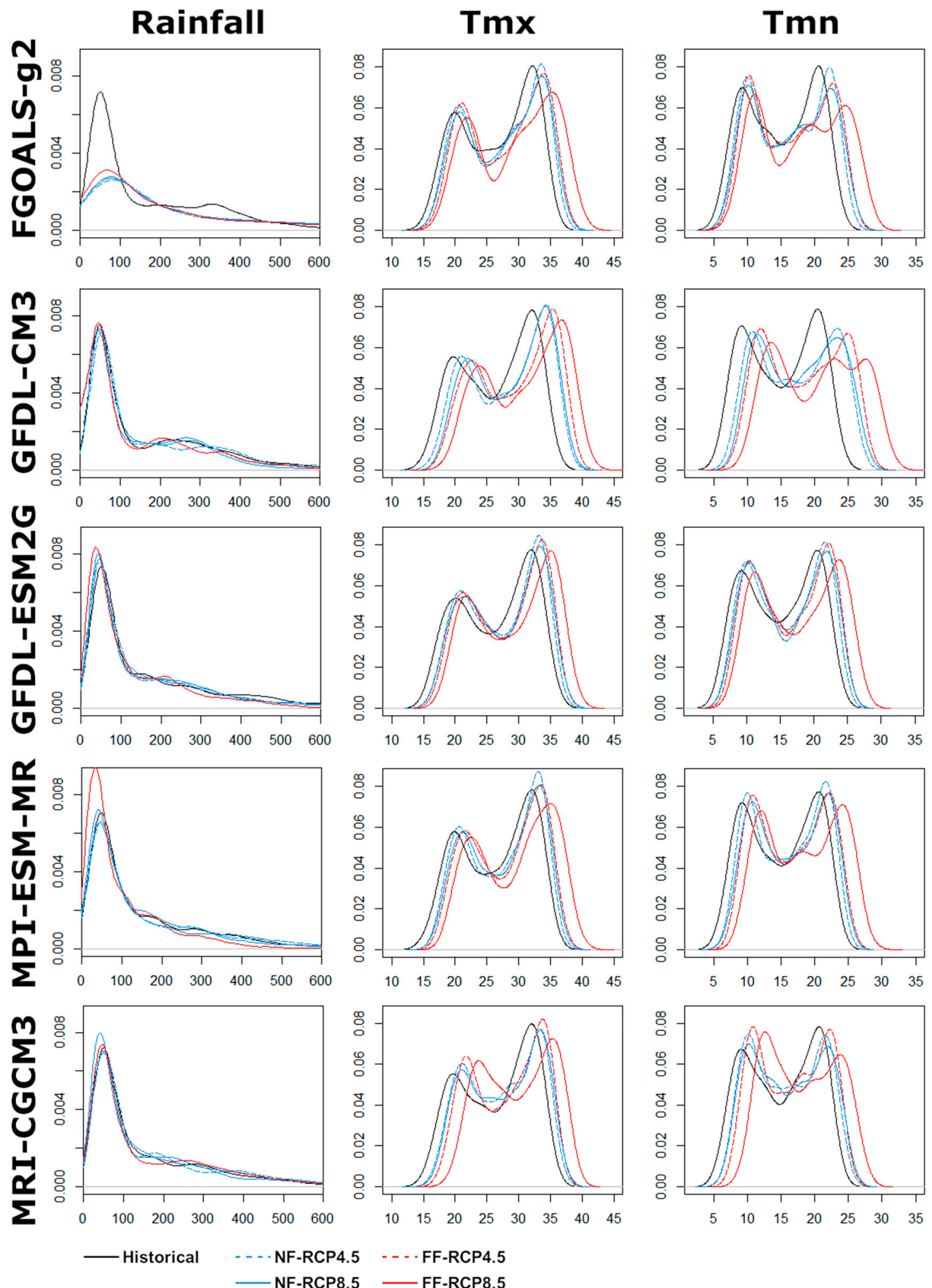

Figure 11. Density plots of the historical and projected bias-corrected annual rainfall and monthly temperatures (columns) for different GCMs (rows). 
(a)

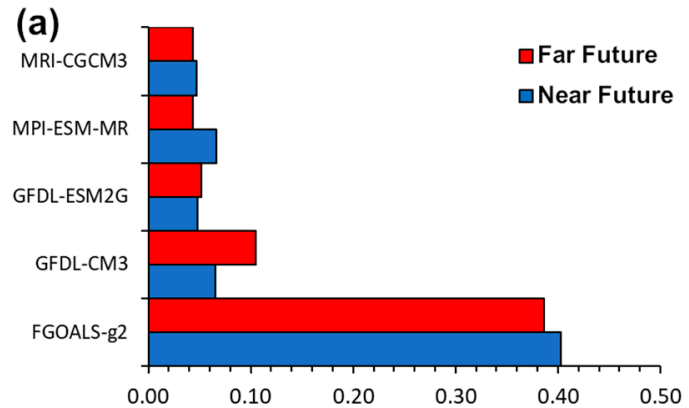

(c)

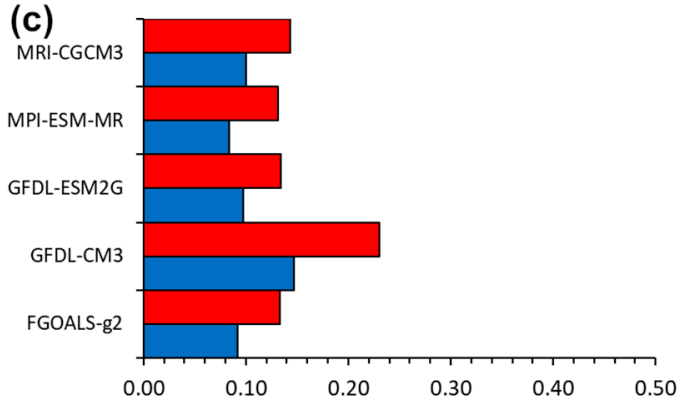

(e)

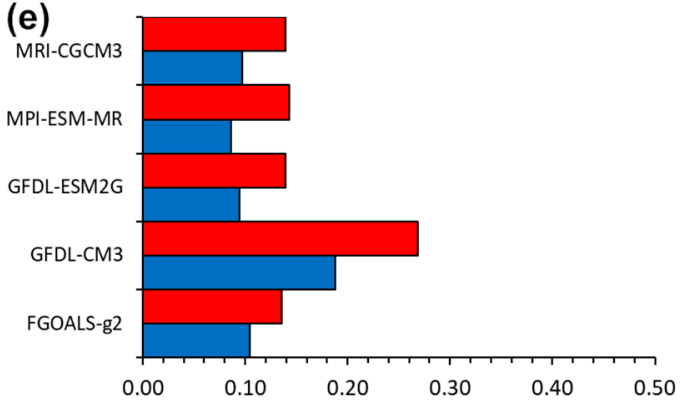

(b)

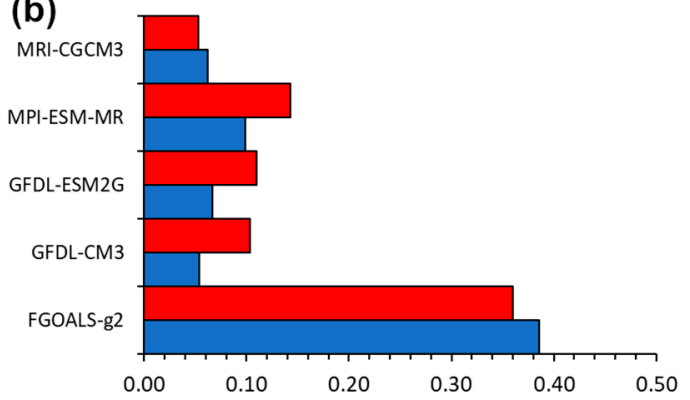

(d)

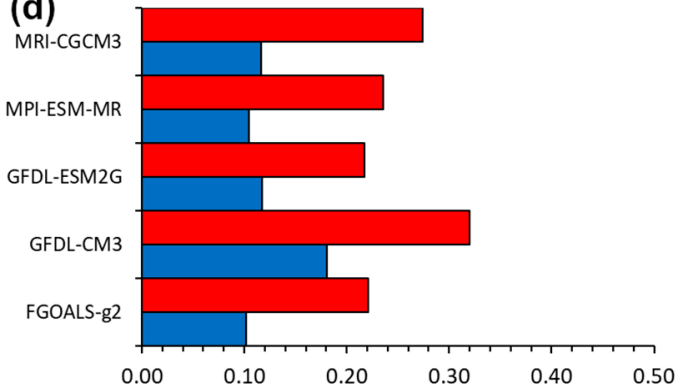

(f)

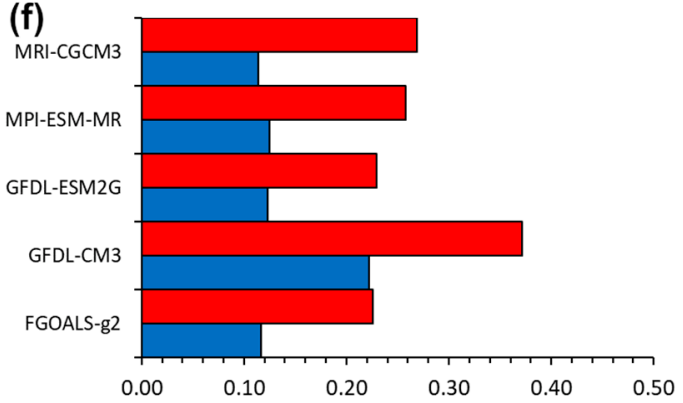

Figure 12. The difference in PDFs (1-PDFss) between the historical and bias-corrected projected data. The left column for RCP4.5 and the right for RCP8.5. The rows present (a,b) rainfall data, (c,d) Tmx, and $(\mathbf{e}, \mathbf{f}) \mathrm{Tmn}$.

\section{Discussion}

Several bias correction methodologies have been proposed to correct the GCMs' outputs on a regional scale before the analysis of the projected change in the climate. These methodologies vary from the simple linear scaling technique to the more advanced quantile mapping techniques. As the performance of downscaling methods varies by case, there is an ongoing need to evaluate their performances in bias-correcting the historical GCM simulations before applying them to the future.

Several studies have reported that raw GCM outputs are always biased [16,81]. The direct use of their raw outputs in climate change is not advisable as they might lead to misleading conclusions about future change. The results of the present study (Figures 5 and 6) also proved that raw GCMs underestimate the historical rainfall in the CNE. Also, most of the raw GCMs underestimate Tmx and overestimate Tmn.

All used bias correction methods showed their capability in improving the GCM outputs at different levels of accuracy. The two simplest methods, linear and variance scaling, were found to be the best methods in bias-correcting the rainfall and temperatures, respectively, of the different GCMs. Both methods showed better statistics compared to others. The scatter and density plots also proved the improvement in their bias-corrected estimates compared to raw GCMs outputs. Other related studies also found that both methods are better in correcting the biases in climate variables [82-84].

It has been argued that in climate change studies, the most relevant result is the climate change signal and not absolute values [85]. In this study, lower climate change signals for rainfall (except 
for RCP8.5) and temperatures were obtained for the bias-corrected future climate data than for the noncorrected data. The projected changes in Tmx and Tmn were smaller using the bias-corrected data than using the raw signals of GCMs presented in Nashwan and Shahid [36]. However, in the case of rainfall, higher climate change signals were obtained for different GCMs, especially for RCP8.5.

The high-resolution projections showed a rise in maximum $\left(1.80-3.48{ }^{\circ} \mathrm{C}\right)$ and minimum $\left(1.88-3.49^{\circ} \mathrm{C}\right)$ temperature and change in rainfall depth $(-96.04-36.51 \%)$ by the end of the century in CNE. This finding complies with the finding of Tabari and Willems [86] with respect to the fact that the dry areas are getting wetter and the wet areas are getting drier in the Middle East, as opposed to the general concept of "wet gets wetter and dry gets drier" [87]. Based on the previous studies [88,89], the projected decrease in rainfall amount is linked to the weakening of the Eastern Mediterranean storm track. Also, the finding of this study agrees with Mostafa et al. [9] in regards to the projected rate of increase in temperature and decrease in rainfall in CNE at three stations' locations.

Nashwan and Shahid [36] found the five GCMs used in this study to be the most capable of replicating the spatial and temporal variability of historical patterns of the three climatic variables, collectively. Which means, that they did not consider the models that had a poor past-performance in any of the three variables, even if they were performing well for the others. However, there is an intermodel variability in the performance of the selected GCMs for different variables. This is evidenced by the ranks obtained from different GCMs presented in Nashwan and Shahid [36] and summarized in Section 2.3. Due to their distinctive performances, the projected changes in FGOALS-g2 and GFDL-CM3 were found to be distinct from those from the remaining GCMs (Figure 10). Furthermore, the remaining models were more likely to project closer climatic conditions because of their adjacent ranks, thus they are positioned close to each other in the plot of Figure 10.

The bias-corrected models' outputs projected a reduction in rainfall during the far future, which would make the winter rainfed cropland become completely irrigation dependent. Furthermore, the possible reduction in rainfall would limit the groundwater recharge, which certainly increases the seawater intrusion from the Mediterranean Sea in the Nile Delta aquifer, which is severely susceptible to seawater intrusion at present [90]. The decrease in future rainfall coupled with the increase in temperature may increase the evapotranspiration, resulting in a reduction of atmospheric water availability, thus increasing irrigation water demand. This may increase agricultural water stress in the country [91], leading to more frequent crop failures. The anticipated decrease in rainfall and increase in temperature shall increase the aridity in the CNE. These changes have been reported in different regions and countries nearby to the CNE [92,93]. The increase in aridity in CNE could lead to a reduction in the crop yield due to the increase of water stress in agriculture land. This may severely affect food security in Egypt as most of the agriculture land is located in this region.

Bias correction methodologies generally assume that the deviation found between the raw GCMs outputs and the historical observations data remain constant over time in the future. This can be doubtful, as it was argued by Lafon, et al. [69] that the downscaling can be sensitive to the selection of the reference period. They found that the LS is more robust and least sensitive to the choice of the calibration period, while the empirical quantile mapping method can be highly accurate, but very sensitive to the choice of the calibration period. Therefore, it should be kept in mind that downscaling and bias correction introduce additional uncertainties, which are greater for higher-order moments.

\section{Conclusions}

This work provided a picture of the future climate conditions expected in the $\mathrm{CNE}$, as projected by a credible subset GCMs over Egypt. Different bias correction methods have been applied to correct the bias in the five interpolated GCMs' outputs onto a high-resolution horizontal grid. The LS and Var were found to be better for bias-correcting rainfall and temperatures of historical GCMs, respectively. They were used to transfer the correction factor to the projections under two RCPs.

The five statistically bias-corrected climate projections presented the uncertainty range in the future change in the climate of CNE. The rainfall is expected to increase in the near future but drastically 
decrease in the far future. The Tmx and Tmn are projected to increase in both the future periods, reaching to 5.50 and $8.50{ }^{\circ} \mathrm{C}$, respectively. These findings highlighted the severe consequence of climate change on the socioeconomic activities in the heavily populated CNE. While much work remains to be done for the indepth impact study, the high-resolution climate projections developed in this study would help to bridge the gap between climate and impact models.

Future work is warranted to increase the reliability and credibility of climate projections over the CNE by forming a multi-model ensemble by using the downscaled GCMs' outputs.

Author Contributions: Conceptualization, M.S.N. and S.S.; methodology, M.S.N. and E.-S.C.; writing-original draft preparation, M.S.N.; writing-review and editing, S.S. and E.-S.C. All authors have read and agreed to the published version of the manuscript.

Funding: This study was supported by the Research Program funded by the SeoulTech (Seoul National University of Science and Technology).

Conflicts of Interest: The authors declare no conflict of interest. The funders had no role in the design of the study; in the collection, analyses, or interpretation of data; in the writing of the manuscript, or in the decision to publish the results.

\section{References}

1. Bouras, E.; Jarlan, L.; Khabba, S.; Er-Raki, S.; Dezetter, A.; Sghir, F.; Tramblay, Y. Assessing the impact of global climate changes on irrigated wheat yields and water requirements in a semi-arid environment of Morocco. Sci. Rep. 2019, 9, 19142. [CrossRef] [PubMed]

2. Giorgi, F. Climate change hot-spots. Geophys. Res. Lett. 2006, 33. [CrossRef]

3. Frölicher, T.L.; Laufkötter, C. Emerging risks from marine heat waves. Nat. Commun. 2018, 9, 650. [CrossRef] [PubMed]

4. Wei, N.; Zhou, L.; Dai, Y.; Xia, G.; Hua, W. Observational Evidence for Desert Amplification Using Multiple Satellite Datasets. Sci. Rep. 2017, 7, 2043. [CrossRef]

5. Nashwan, M.S.; Shahid, S.; Abd Rahim, N. Unidirectional trends in annual and seasonal climate and extremes in Egypt. Theor. Appl. Climatol. 2019, 136, 457-473. [CrossRef]

6. Gado, T.A.; El-Hagrsy, R.M.; Rashwan, I.M.H. Spatial and temporal rainfall changes in Egypt. Env. Sci Pollut. Res. Int. 2019, 26, 28228-28242. [CrossRef]

7. Beniston, M.; Stephenson, D.B.; Christensen, O.B.; Ferro, C.A.T.; Frei, C.; Goyette, S.; Halsnaes, K.; Holt, T.; Jylhä, K.; Koffi, B.; et al. Future extreme events in European climate: An exploration of regional climate model projections. Clim. Chang. 2007, 81, 71-95. [CrossRef]

8. Zhou, L. Desert Amplification in a Warming Climate. Sci. Rep. 2016, 6, 31065. [CrossRef]

9. Mostafa, A.N.; Wheida, A.; El Nazer, M.; Adel, M.; El Leithy, L.; Siour, G.; Coman, A.; Borbon, A.; Magdy, A.W.; Omar, M.; et al. Past (1950-2017) and future (-2100) temperature and precipitation trends in Egypt. Weather Clim. Extrem. 2019, 26, 100225. [CrossRef]

10. Demirel, M.C.; Moradkhani, H. Assessing the impact of CMIP5 climate multi-modeling on estimating the precipitation seasonality and timing. Clim. Chang. 2016, 135, 357-372. [CrossRef]

11. Ahmed, K.; Sachindra, D.A.; Shahid, S.; Demirel, M.C.; Chung, E.S. Selection of multi-model ensemble of general circulation models for the simulation of precipitation and maximum and minimum temperature based on spatial assessment metrics. Hydrol. Earth Syst. Sci. 2019, 23, 4803-4824. [CrossRef]

12. Salman, S.A.; Shahid, S.; Ismail, T.; Ahmed, K.; Wang, X.J. Selection of climate models for projection of spatiotemporal changes in temperature of Iraq with uncertainties. Atmos. Res. 2018, 213, 509-522. [CrossRef]

13. Shourav, M.S.A.; Shahid, S.; Singh, B.; Mohsenipour, M.; Chung, E.-S.; Wang, X.-J. Potential Impact of Climate Change on Residential Energy Consumption in Dhaka City. Environ. Modeling Assess. 2018, 23, 131-140. [CrossRef]

14. Sung, J.H.; Chung, E.-S.; Shahid, S. Reliability-Resiliency-Vulnerability Approach for Drought Analysis in South Korea Using 28 GCMs. Sustainability 2018, 10, 3043. [CrossRef]

15. Shiru, M.S.; Shahid, S.; Shiru, S.; Chung, E.S.; Alias, N.; Ahmed, K.; Dioha, E.C.; Sa'adi, Z.; Salman, S.; Noor, M.; et al. Challenges in water resources of Lagos mega city of Nigeria in the context of climate change. J. Water Clim. Chang. 2019. [CrossRef] 
16. Noor, M.; Ismail, T.; Shahid, S.; Salem Nashwan, M.; Ullah, S. Development of multi-model ensemble for projection of extreme rainfall events in Peninsular Malaysia. Hydrol. Res. 2019. [CrossRef]

17. Brown, J.R.; Jakob, C.; Haynes, J.M. An Evaluation of Rainfall Frequency and Intensity over the Australian Region in a Global Climate Model. J. Clim. 2010, 23, 6504-6525. [CrossRef]

18. Lutz, A.F.; ter Maat, H.W.; Biemans, H.; Shrestha, A.B.; Wester, P.; Immerzeel, W.W. Selecting representative climate models for climate change impact studies: An advanced envelope-based selection approach. Int. J. Climatol. 2016, 36, 3988-4005. [CrossRef]

19. Cannon, A.J. Selecting GCM Scenarios that Span the Range of Changes in a Multimodel Ensemble: Application to CMIP5 Climate Extremes Indices. J. Clim. 2015, 28, 1260-1267. [CrossRef]

20. Sa'adi, Z.; Shahid, S.; Chung, E.S.; bin Ismail, T. Projection of spatial and temporal changes of rainfall in Sarawak of Borneo Island using statistical downscaling of CMIP5 models. Atmos. Res. 2017, 197, 446-460. [CrossRef]

21. Evans, J.; McGregor, J.; McGuffie, K. Chapter 9-Future Regional Climates. In The Future of the World's Climate, 2nd ed.; Henderson-Sellers, A., McGuffie, K., Eds.; Elsevier: Boston, MA, USA, 2012; pp. 223-250.

22. Denis, B.; Laprise, R.; Caya, D.; Cote, J. Downscaling ability of one-way nested regional climate models: The Big-Brother Experiment. Clim. Dyn. 2002, 18, 627-646. [CrossRef]

23. Sachindra, D.A.; Ahmed, K.; Rashid, M.M.; Shahid, S.; Perera, B.J.C. Statistical downscaling of precipitation using machine learning techniques. Atmos. Res. 2018, 212, 240-258. [CrossRef]

24. Wilby, R.L.; Wigley, T.M.L.; Conway, D.; Jones, P.D.; Hewitson, B.C.; Main, J.; Wilks, D.S. Statistical downscaling of general circulation model output: A comparison of methods. Water Resour. Res. 1998, 34, 2995-3008. [CrossRef]

25. Stanley, D.J.; Warne, A.G. Nile delta: Recent geological evolution and human impact. Science 1993, 260, 628-634. [CrossRef] [PubMed]

26. Kimura, R.; Kato, H.; Iwasaki, E. Cultivation Features Using Meteorological and Satellite Data from 2001 to 2010 in Dakhla Oasis, Egypt. J. Water Resour. Prot. 2015, 7, 209. [CrossRef]

27. El Kenawy, A.M.; Hereher, M.E.; Robaa, S.M. An Assessment of the Accuracy of MODIS Land Surface Temperature over Egypt Using Ground-Based Measurements. Remote Sens. 2019, 11, 2369. [CrossRef]

28. Strzepek, K.M.; Yates, D.N.; Quosy, D.E.D.E. Vulnerability assessment of water resources in Egypt to climatic change in the Nile Basin. Clim. Res. 1996, 89-95. [CrossRef]

29. El-Raey, M. Vulnerability assessment of the coastal zone of the Nile delta of Egypt, to the impacts of sea level rise. Ocean Coast. Manag. 1997, 37, 29-40. [CrossRef]

30. Yates, D.N.; Strzepek, K.M. An assessment of integrated climate change impacts on the agricultural economy of Egypt. Clim. Chang. 1998, 38, 261-287. [CrossRef]

31. El-Nahry, A.H.; Doluschitz, R. Climate change and its impacts on the coastal zone of the Nile Delta, Egypt. Environ. Earth Sci. 2010, 59, 1497-1506. [CrossRef]

32. Susnik, J.; Vamvakeridou-Lyroudia, L.S.; Baumert, N.; Kloos, J.; Renaud, F.G.; La Jeunesse, I.; Mabrouk, B.; Savic, D.A.; Kapelan, Z.; Ludwig, R.; et al. Interdisciplinary assessment of sea-level rise and climate change impacts on the lower Nile delta, Egypt. Sci. Total Env. 2015, 503-504, 279-288. [CrossRef] [PubMed]

33. Agrawala, S.; Moehner, A.; El Raey, M.; Conway, D.; Van Aalst, M.; Hagenstad, M.; Smith, J. Development and Climate Change in Egypt: Focus on Coastal Resources and the Nile; Organisation for Economic Co-operation and Development: Paris, France, 2004; p. 68.

34. Shaltout, M.; Tonbol, K.; Omstedt, A. Sea-level change and projected future flooding along the Egyptian Mediterranean coast. Oceanologia 2015, 57, 293-307. [CrossRef]

35. Mabrouk, M.B.; Jonoski, A.; Solomatine, D.; Uhlenbrook, S. A review of seawater intrusion in the Nile Delta groundwater system-the basis for assessing impacts due to climate changes and water resources development. Hydrol. Earth Syst. Sci. Discuss. 2013, 10, 10873-10911. [CrossRef]

36. Nashwan, M.S.; Shahid, S. A novel framework for selecting general circulation models based on the spatial patterns of climate. Int. J. Climatol. 2020. [CrossRef]

37. Anwar, S.A.; Zakey, A.S.; Robaa, S.M.; Abdel Wahab, M.M. The influence of two land-surface hydrology schemes on the regional climate of Africa using the RegCM4 model. Theor. Appl. Climatol. 2019, 136, 1535-1548. [CrossRef]

38. Knox, J.; Hess, T.; Daccache, A.; Wheeler, T. Climate change impacts on crop productivity in Africa and South Asia. Env. Res. Lett. 2012, 7, 034032. [CrossRef] 
39. Füssel, H.-M.; Jol, A. Climate Change, Impacts and Vulnerability in Europe 2012 an Indicator-Based Report; 12/2012; European Environment Agency: Copenhagen, Denmark, 2012.

40. Prein, A.F.; Gobiet, A. Impacts of uncertainties in European gridded precipitation observations on regional climate analysis. Int. J. Clim. 2017, 37, 305-327. [CrossRef]

41. Nashwan, M.S.; Shahid, S.; Wang, X.J. Assessment of Satellite-Based Precipitation Measurement Products over the Hot Desert Climate of Egypt. Remote Sens. 2019, 11, 555. [CrossRef]

42. Nashwan, M.S.; Shahid, S.; Chung, E.-S. Development of high-resolution daily gridded temperature datasets for the central north region of Egypt. Sci. Data 2019, 6, 138. [CrossRef]

43. Novella, N.S.; Thiaw, W.M. African Rainfall Climatology Version 2 for Famine Early Warning Systems. J. Appl. Meteorol. Climatol. 2013, 52, 588-606. [CrossRef]

44. CAPMAS. Egypt in Figures 2019—Census, March 2019 ed.; Central Agency for Public Mobilization And Statistics (CAPMAS): Cairo, Egypt, 2019; Volume 1, pp. 16-32.

45. Hereher, M.E. The status of Egypt's agricultural lands using MODIS Aqua data. Egypt. J. Remote Sens. Space Sci. 2013, 16, 83-89. [CrossRef]

46. Shibasaki, R.; Azuma, T.; Yoshida, T.; Teranishi, H.; Abe, M. Global route choice and its modelling of dry bulk carriers based on vessel movement database: Focusing on the Suez Canal. Res. Transp. Bus. Manag. 2017, 25, 51-65. [CrossRef]

47. Nashwan, M.S.; Shahid, S. Symmetrical uncertainty and random forest for the evaluation of gridded precipitation and temperature data. Atmos. Res. 2019, 230, 104632. [CrossRef]

48. El Kenawy, A.; Lopez-Moreno, J.I.; Vicente-Serrano, S.M.; Morsi, F. Climatological modeling of monthly air temperature and precipitation in Egypt through GIS techniques. Clim. Res. 2010, 42, 161-176. [CrossRef]

49. McGinnis, S.; Nychka, D.; Mearns, L.O. A New Distribution Mapping Technique for Climate Model Bias Correction. In Proceedings of the 4th International Workshop on Climate Informatics Machine Learning and Data Mining Approaches to Climate Science, Cham, Switzerland, 25-26 September 2014; pp. 91-99.

50. Fick, S.E.; Hijmans, R.J. WorldClim 2: New 1-km spatial resolution climate surfaces for global land areas. Int. J. Climatol. 2017, 37, 4302-4315. [CrossRef]

51. Nashwan, M.S.; Shahid, S.; Chung, E.-S. Central North Region of Egypt (CNE) Maximum and Minimum Temperature Gridded Datasets. Figshare 2019. [CrossRef]

52. Nashwan, M.S.; Shahid, S.; Dewan, A.; Ismail, T.; Alias, N. Performance of five high resolution satellite-based precipitation products in arid region of Egypt: An evaluation. Atmos. Res. 2020, 236, 104809. [CrossRef]

53. Schmidli, J.; Frei, C.; Vidale, P.L. Downscaling from GCM precipitation: a benchmark for dynamical and statistical downscaling methods. Int. J. Climatol. 2006, 26, 679-689. [CrossRef]

54. Sunyer, M.A.; Madsen, H.; Ang, P.H. A comparison of different regional climate models and statistical downscaling methods for extreme rainfall estimation under climate change. Atmos. Res. 2012, 103, 119-128. [CrossRef]

55. Chen, J.; Chen, H.; Guo, S. Multi-site precipitation downscaling using a stochastic weather generator. Clim. Dyn. 2018, 50, 1975-1992. [CrossRef]

56. Eden, J.M.; Widmann, M.; Grawe, D.; Rast, S. Skill, Correction, and Downscaling of GCM-Simulated Precipitation. J. Clim. 2012, 25, 3970-3984. [CrossRef]

57. Chen, J.; Brissette, F.P.; Leconte, R. Assessing regression-based statistical approaches for downscaling precipitation over North America. Hydrol. Process. 2014, 28, 3482-3504. [CrossRef]

58. Eden, J.M.; Widmann, M.; Maraun, D.; Vrac, M. Comparison of GCM-and RCM-simulated precipitation following stochastic postprocessing. J. Geophys. Res. Atmos. 2014, 119. [CrossRef]

59. Pour, S.H.; Shahid, S.; Chung, E.-S.; Wang, X.-J. Model output statistics downscaling using support vector machine for the projection of spatial and temporal changes in rainfall of Bangladesh. Atmos. Res. 2018. [CrossRef]

60. Eden, J.M.; Widmann, M. Downscaling of GCM-Simulated Precipitation Using Model Output Statistics. J. Clim. 2014, 27, 312-324. [CrossRef]

61. Turco, M.; Quintana-Segui, P.; Llasat, M.C.; Herrera, S.; Gutierrez, J.M. Testing MOS precipitation downscaling for ENSEMBLES regional climate models over Spain. J. Geophys. Res. Atmos. 2011, 116. [CrossRef]

62. Turco, M.; Llasat, M.C.; Herrera, S.; Gutiérrez, J.M. Bias correction and downscaling of future RCM precipitation projections using a MOS-Analog technique. J. Geophys. Res. Atmos. 2017, 122, 2631-2648. [CrossRef] 
63. Castellano, C.M.; DeGaetano, A.T. Downscaling Extreme Precipitation from CMIP5 Simulations Using Historical Analogs. J. Appl. Meteorol. Climatol. 2017, 56, 2421-2439. [CrossRef]

64. Elshamy, M.; Seierstad, I.A.; Sorteberg, A. Impacts of climate change on Blue Nile flows using bias-corrected GCM scenarios. Hydrol. Earth Syst. Sci. 2009. [CrossRef]

65. Sharma, D.; Gupta, A.D.; Babel, M. Spatial disaggregation of bias-corrected GCM precipitation for improved hydrologic simulation: Ping River Basin, Thailand. Hydrol. Earth Syst. Sci. Discuss. 2007, 11, 1373-1390. [CrossRef]

66. Wang, L.; Chen, W. A CMIP5 multimodel projection of future temperature, precipitation, and climatological drought in China. Int. J. Climatol. 2014, 34, 2059-2078. [CrossRef]

67. Müller, M.F.; Thompson, S.E. Bias adjustment of satellite rainfall data through stochastic modeling: Methods development and application to Nepal. Adv. Water Resour. 2013, 60, 121-134. [CrossRef]

68. Lenderink, G.; Buishand, A.; van Deursen, W. Estimates of future discharges of the river Rhine using two scenario methodologies: Direct versus delta approach. Hydrol. Earth Syst. Sci. 2007, 11, 1143-1159. [CrossRef]

69. Lafon, T.; Dadson, S.; Buys, G.; Prudhomme, C. Bias correction of daily precipitation simulated by a regional climate model: A comparison of methods. Int. J. Climatol. 2013, 33, 1367-1381. [CrossRef]

70. Diaz-Nieto, J.; Wilby, R.L. A comparison of statistical downscaling and climate change factor methods: Impacts on low flows in the River Thames, United Kingdom. Clim. Chang. 2005, 69, 245-268. [CrossRef]

71. Maraun, D.; Wetterhall, F.; Ireson, A.M.; Chandler, R.E.; Kendon, E.J.; Widmann, M.; Brienen, S.; Rust, H.W.; Sauter, T.; Themeßl, M.; et al. Precipitation downscaling under climate change: Recent developments to bridge the gap between dynamical models and the end user. Rev. Geophys. 2010, 48. [CrossRef]

72. Piani, C.; Haerter, J.O.; Coppola, E. Statistical bias correction for daily precipitation in regional climate models over Europe. Theor. Appl. Climatol. 2010, 99, 187-192. [CrossRef]

73. Wilcke, R.A.I.; Mendlik, T.; Gobiet, A. Multi-variable error correction of regional climate models. Clim. Chang. 2013, 120, 871-887. [CrossRef]

74. Amengual, A.; Homar, V.; Romero, R.; Alonso, S.; Ramis, C. A statistical adjustment of regional climate model outputs to local scales: Application to Platja de Palma, Spain. J. Clim. 2012, 25, 939-957. [CrossRef]

75. Leander, R.; Buishand, T.A. Resampling of regional climate model output for the simulation of extreme river flows. J. Hydrol. 2007, 332, 487-496. [CrossRef]

76. Terink, W.; Hurkmans, R.; Uijlenhoet, R.; Warmerdam, P.; Torfs, P. Bias Correction of Temperature and Precipitation Data for Regional Climate Model Application to the Rhine Basin; Wageningen Universiteit: Wageningen, The Netherlands, 2008.

77. Brent, R.P. An algorithm with guaranteed convergence for finding a zero of a function. Comput. J. 1971, 14, 422-425. [CrossRef]

78. Tschöke, G.V.; Kruk, N.S.; de Queiroz, P.I.B.; Chou, S.C.; de Sousa Junior, W.C. Comparison of two bias correction methods for precipitation simulated with a regional climate model. Theor. Appl. Climatol. 2017, 127, 841-852. [CrossRef]

79. Terink, W.; Hurkmans, R.T.W.L.; Torfs, P.J.J.F.; Uijlenhoet, R. Evaluation of a bias correction method applied to downscaled precipitation and temperature reanalysis data for the Rhine basin. Hydrol. Earth Syst. Sci. 2010, 14, 687-703. [CrossRef]

80. Perkins, S.E.; Pitman, A.J.; Sisson, S.A. Systematic differences in future 20 year temperature extremes in AR4 model projections over Australia as a function of model skill. Int. J. Climatol. 2013, 33, 1153-1167. [CrossRef]

81. Luo, M.; Liu, T.; Meng, F.H.; Duan, Y.C.; Frankl, A.; Bao, A.M.; De Maeyer, P. Comparing Bias Correction Methods Used in Downscaling Precipitation and Temperature from Regional Climate Models: A Case Study from the Kaidu River Basin in Western China. Water 2018, 10, 1046. [CrossRef]

82. Ouyang, F.; Zhu, Y.H.; Fu, G.B.; Lu, H.S.; Zhang, A.J.; Yu, Z.B.; Chen, X. Impacts of climate change under CMIP5 RCP scenarios on streamflow in the Huangnizhuang catchment. Stoch. Environ. Res. Risk Assess. 2015, 29, 1781-1795. [CrossRef]

83. Akhtar, M.; Ahmad, N.; Booij, M.J. Use of regional climate model simulations as input for hydrological models for the Hindukush-Karakorum-Himalaya region. Hydrol. Earth Syst. Sci. 2009, 13, 1075-1089. [CrossRef]

84. Mpelasoka, F.S.; Chiew, F.H.S. Influence of Rainfall Scenario Construction Methods on Runoff Projectios. J. Hydrometeorol. 2009, 10, 1168-1183. [CrossRef] 
85. Worner, V.; Kreye, P.; Meon, G. Effects of Bias-Correcting Climate Model Data on the Projection of Future Changes in High Flows. Hydrology 2019, 6, 46. [CrossRef]

86. Tabari, H.; Willems, P. More prolonged droughts by the end of the century in the Middle East. Env. Res. Lett. 2018, 13, 104005. [CrossRef]

87. Hu, Z.; Chen, X.; Chen, D.; Li, J.; Wang, S.; Zhou, Q.; Yin, G.; Guo, M. "Dry gets drier, wet gets wetter": A case study over the arid regions of central Asia. Int. J. Climatol. 2019, 39, 1072-1091. [CrossRef]

88. Evans, J.P. 21st century climate change in the Middle East. Clim. Chang. 2009, 92, 417-432. [CrossRef]

89. Evans, J.P. Global warming impact on the dominant precipitation processes in the Middle East. Theor. Appl. Climatol. 2010, 99, 389-402. [CrossRef]

90. Abd-Elhamid, H.; Javadi, A.; Abdelaty, I.; Sherif, M. Simulation of seawater intrusion in the Nile Delta aquifer under the conditions of climate change. Hydrol. Res. 2016, 47, 1198-1210. [CrossRef]

91. Hassan, A.; Ismail, S.S.; Elmoustafa, A.; Khalaf, S. Evaluating evaporation rate from high Aswan Dam Reservoir using RS and GIS techniques. Egypt. J. Remote Sens. Space Sci. 2018, 21, 285-293. [CrossRef]

92. Şarlak, N.; Mahmood Agha, O.M.A. Spatial and temporal variations of aridity indices in Iraq. Theor. Appl. Climatol. 2018, 133, 89-99. [CrossRef]

93. Batanouny, K.H. Climatic Aridity in the Deserts of the Middle East. In Plants in the Deserts of the Middle East; Springer: Berlin/Heidelberg, Germany, 2001; pp. 11-24. [CrossRef]

(C) 2020 by the authors. Licensee MDPI, Basel, Switzerland. This article is an open access article distributed under the terms and conditions of the Creative Commons Attribution (CC BY) license (http://creativecommons.org/licenses/by/4.0/). 